\title{
A Project Management System Based on the PMBOK Guide for Student-Centered Learning
}

\author{
Chulhyun Kim, Jeonghwan Jeon, and Moon-Soo Kim
}

\begin{abstract}
This study deals with development of a web-based project management system based on the project management body of knowledge (PMBOK) developed by the PMI to support the operation of capstone course for student-centered learning in engineering education. The developed web-based project management system not only enables to encourage participant-directed learning through managing the team project execution by students themselves, but provides teaching staff with operation and monitoring of the whole course. The PMS is expected to provide effective project performance for students and efficient curriculum management for teaching staff.
\end{abstract}

Index Terms-Web-based project management system, project management body of knowledge, student-centered learning, engineering education, capstone course.

\section{INTRODUCTION}

In most engineering school the capstone design course based on student-centered learning seeks to prepare engineering students for work in the industry by challenging teams to synthesize solutions to open-ended, real-world problems, typically through the employment of project-based learning activities based on industrial problems [1], [2]. Usually the capstone course has been applied to senior students as a gate to achieving their academic degree. Typically, in one or two semesters of the course, teams define a problem, plan their approach, propose creative solutions, analyze the proposed solutions, produce or implement the solutions, and then communicate them internally and externally. Participation in capstone design provides students with the opportunity to transition from student communities of practice to professional communities of practices, i.e., from the classroom to real industry. Working with a client-advisor from the field (industrial engineers, start-up companies, company representatives, teaching staffs, laboratories, etc) in a type of apprenticeship, students are challenged with real-world needs. While students of the capstone course are not full members in the professional community, contextualizing the problems, needs, or services within the field's practices provides students with the opportunity for

Manuscript received April 30, 2015; revised June 30, 2015.

Chulhyun Kim is with the Department of Technology and Systems Management, Induk University, Seoul, Republic of Korea (e-mail: stddevs@induk.ac.kr).

Jeonghwan Jeon is with the Department of Industrial and Systems Engineering/ERI/UNICO, Gyeongsang National University, Republic of Korea (e-mail: jhjeon@gnu.ac.kr).

Moon-Soo Kim is with the Department of Industrial and Management Engineering, Hankuk University of Foreign Studies, Yongin, Republic of Korea (corresponding author. e-mail:kms@hufs.ac.kr). situated learning [3] and affords them the opportunity to apply their skills and knowledge toward the development of a robust understanding of what it means to be an engineer. This facilitates an identity shift from student to professional engineer [4].

However, although the capstone course is very essential in engineering school and provides students with real experiences and self-directed learning, the execution of real or quasi-real project based on team work among students produces many problems including routine documentary works, searching information and know-how for problem-solving, managing team work, relationship with client firm and others. So they need a project management system to carry out their project in capstone course as firm's project has been carried out effectively and efficiently using business-use project management system (PMS). We develop a web-based project management system based on the project management body of knowledge (PMBOK) developed by the PMI of the US to support the operation of capstone course for student-centered learning in Industry Engineering.

The remainder of this paper is comprised of 3 sections. We examine the research background in Section II including the student-centered learning trend of engineering education, capstone course in IE and about PMBOK. Section III explains the developed web-based project management system from basic concept and system architecture to menu structure and functions. Section IV provides conclusions including limitations and future researches.

\section{RESEARCH BACKGROUND}

\section{A. Student-Centered Learning and Engineering Education}

Student-centered learning, which refers to the imposition of more responsibility on students for their own learning than the traditional lecture-based approach, is an umbrella encompassing a range of instructional methods, including inquiry learning, problem-based learning, project-based learning, case-based teaching, discovery learning, etc. These methods are all supported by the research findings that students learn by fitting new information into their existing cognitive structures, and are unlikely to learn if the new information has few apparent connections to previous knowledge and beliefs [5]. As most engineering educational institutions are in an ongoing process of transformation from the traditional paradigm, which is discipline-oriented, lecture-centered, and based on basic and applied technical knowledge, to a new, interdisciplinary, contextualized, student-centered paradigm based on a complex understanding of technological knowledge, the implementation of 
problem-based learning $\left(\mathrm{P}_{\mathrm{m}} \mathrm{BL}\right)$ and project-based learning $\left(\mathrm{P}_{\mathrm{t}} \mathrm{BL}\right)$ have been highlighted more and more by those institutions [6].

In terms of theory, the understanding of student-centered learning takes its point of departure in the constructivist socio-cultural approach of understanding learning and education [7], building on the widely accepted principle that students construct their own versions of reality rather than simply absorbing the versions presented by their teachers. The methods almost always involve student discussion about questions and problem solving in class (active learning), with much of the work inside and outside of class being done by students working in groups (collaborative or cooperative learning). Many different variations of student-centered learning practices may be identified, ranging from the large-scale implementation of student-centered learning at a departmental or institutional level, to the small-scale implementation in a single course [6].

$\mathrm{P}_{\mathrm{m}} \mathrm{BL}$ is a learning process based on a peculiar problem case under the need-to-know method [8]. For appropriate application of the $\mathrm{P}_{\mathrm{m}} \mathrm{BL}$ model to engineering education, $\mathrm{P}_{\mathrm{m}} \mathrm{BL}$ needs a multidisciplinary approach that can provide information and knowledge, as well as certainty, to engineering students dealing with problems with which they are not experienced and that are ill-structured [9]. In addition, under the $\mathrm{P}_{\mathrm{m}} \mathrm{BL}$ environment, teachers or educators are not a source of knowledge, but should instead be the guide or coach facilitating the process of knowledge acquisition for the students [10], [11]. The $\mathrm{P}_{\mathrm{t}} \mathrm{BL}$ model in the engineering school is a kind of $\mathrm{P}_{\mathrm{m}} \mathrm{BL}$, since project work is problem-based by definition and its process usually deals with problems from real industry sectors. The $\mathrm{P}_{\mathrm{t}} \mathrm{BL}$ process of ill-structured problems requires the employment of various multi-disciplinary fields to yield solutions to the real industrial problems [9]-[14]. In identifying how to reach the project goal, the members of a team have to learn to co-operate effectively. This creates good conditions for learning, as it involves both individual and co-operative activities, as well as interactive discussions and a writing process (mostly in the form of a project report). Project work teaches competencies such as project management and co-operation. Project assignments are also highly challenging. The more the task reflects reality, the more the students feel motivated, so working on a project can be seen as a way to organize various simultaneous and/or integrated learning processes [15]. Therefore, it is crucial for the students in a $\mathrm{P}_{\mathrm{t}} \mathrm{BL}$ curriculum to become lifelong learners who have learned to take responsibility for their own learning process. This is why the capstone course of senior students is deep associated with the $\mathrm{P}_{\mathrm{t}} \mathrm{BL}$ process.

\section{B. Course Framework and Description of IE Capstone}

The industrial engineering capstone course of Hankuk University of Foreign Studies (HUFS) in Korea lasts 15 weeks, and is mandatory for undergraduate IE students in their seventh semester. Students are required to work in teams formulated of 3-5 students in order to develop a real project. Although the projects are based on real problems, they come in diverse types: projects formulated by students themselves from needs of the industrial sector, projects proposed by faculty members from their private or public contract R\&D projects, projects proposed by the needs within the engineering school, projects based on subjects of competitive exhibitions held by outside institutions, etc. Among the various types, student-owned projects are typical, and have been encouraged by this course. While execution of the course during one semester is based on the general procedures of project management by every project team without lectures, consisting of 3 regular steps including the proposal, interim and final evaluation, the preparatory step undertaken by students before the start of the course is very important for team formulation, project selection and pre-survey about their project, etc., and the post step for the application of the project results obtained is essential for their future carriers. Thus, the overall capstone course may be comprised of 3 courses: a pre-course, as preparatory study; a class-course, as a regular course; and post-course, including typical application activities.

The pre-course of capstone is usually carried out for 4 to 6 weeks during the vacation season prior to the new semester. At that time, students spontaneously formulate project teams with a minimum of 3 to a maximum of 5 members. Every team then receives an industrial problem from a service or manufacturing company provided by the faculty members, alumni or the team itself, and prepares to solve the team project through identification and definition of the team problem, survey of the target company, which can be a client, making an execution plan, including assigning detail tasks to team members, and execution of student-centered learning to gain the relevant knowledge and information about the problem and company. Although students meet the faculty members for discussion and advice about the problem during the pre-course, all activities and learning for project formulation are autonomously carried out by students. At the end of the pre-course, each team prepares a project proposal and an oral presentation.

The class-course of capstone, which is a 5-credit class with a teacher in charge and the advisor-to-team, begins with oral presentations by all teams in the first week, which is an official event open to the all students of the IE department, after which the proposals reflecting the faculty members' comments and peer review are submitted in the following week. Throughout the duration of the course, all teams carry out their projects through collaborative learning, weekly meetings with advisors, and communication with their industrial clients. Although there are no official lectures, monitoring and control of the progress of all capstone projects is performed through oral presentations of the intermediate results, and the mid-term and final-term outputs of each team are officially evaluated by all faculty members and peer review as done for the proposal evaluation step. In the case of industrial projects, the outputs are then delivered to the related companies, whose feedback must be included in the final report, which signals the end of the class. The students' grades are determined on the basis of the 3 evaluations, peer review and/or company feedback, including on the quality of the project output, as well as the advisors' judgment on how well the team worked together and kept to schedule.

The post-course is for utilizing the project outputs to help students in their future carriers. It contains areas such as 
financial support, advice by faculty members, and relevant information and institutional assistance when submitting the project output to a university, inside or outside competition exhibition, submitting papers to academic journals, and patent application.

From the birth of the IE capstone course to the present, the overall process has been managed by the traditional teaching methods in a class. Such off-line management has shown several pitfalls in both of course management of the teaching staff and project management of the student teams. The capstone course-specific features require historical records linked to previous projects, which would enable students to search for and define projects without much time consumption, as well as to obtain effective and efficient methodologies with which to solve their problems if the capstone course history were to be available on an on-line system. Furthermore, the on-line management of the capstone course can provide teaching staff as well as student teams with more efficient monitoring and progress control for the capstone projects. So we believe that a web-based project management system helps students make an effective an efficient progress their projects as well as teaching-staff manage the capstone course efficiently.

\section{Project Management Body of Knowledge (PMBOK)}

In order to succeed the capstone project, students are required an appropriate project management which is also necessary for teaching staff and regarding participants to operate the effective and efficient capstone course. The increasing acceptance of project management indicates that the application of appropriate knowledge, processes, skills, tools, and techniques can have a significant impact on project success. The PMBOK [16], which was developed by the Project Management Institute (PMI) of the US in 1996 and published the $4^{\text {th }}$ edition in 2011, identifies that subset of the project management body of knowledge and generally recognized as good practice. "Generally recognized" means the knowledge and practices described are applicable to most projects most of the time, and there is consensus about their value and usefulness. "Good practice" means there is general agreement that the application of these skills, tools, and techniques can enhance the chances of success over a wide range of projects. Good practice does not mean the knowledge described should always be applied uniformly to all projects; the organization and/or project management team is responsible for determining what is appropriate for any given project.

The core of project management of PMI is on knowledge necessary for the processes within project management which are organized into nine knowledge areas: 1) project integration management for the process required to ensure that the various elements of the project are properly coordinated; 2) project scope management for the process required to ensure that the project includes all the work required, and only the work required, to complete the project successfully; 3) project time management for the process required to ensure timely completion of the project; 4) project cost management for the process required to ensure the project is completed within the approved budge; 5) project quality management for the process required to ensure the project will satisfy the needs for which it was undertaken; 6) project human resource management for the process required to make the most effective use of the people involved with the project; 7) project communications management for the process required to ensure timely and appropriate generation, collection, dissemination, storage and ultimate disposition of project information; 8) project risk management for the process concerned with identifying, analyzing, and responding to project risk; 9) project procurement management for the process required to acquire goods and services from outside the performing organization [16].

Since, aforementioned, the PMBOK is a body of knowledge generally recognized as good practice, the core contents of knowledge areas, when applying them to the capstone course, have to be revised considering educational contextual situation including facilitating student-centered learning and pedagogical purpose, i.e., to discipline- and course-specific project management. In section 3, we develop a web-based project management system of Industrial Engineering capstone course, which is for discipline- and course-specific project management based on PMBOK, to help students themselves execute their projects effectively and efficiently.

\section{WEB-BASED PMS FOR IE CAPSTONE}

\section{A. Basic Concept of Web-Based PMS for IE Capstone}

The capstone course-specific features, which are deep associated with the $\mathrm{P}_{\mathrm{t}} \mathrm{BL}$ process among student-centered learning models, require historical records linked to previous projects as well as to obtain effective and efficient methodologies with which to solve their problems if the capstone course history were to be available on a web-based system. Furthermore, the web-based system of the capstone course can provide teaching staff as well as student teams with more efficient monitoring and progress control for the capstone projects. In order to construct the web-based project management system of the capstone course, the PMBOK model, the PMI's general project management model, is adopted and adapted for facilitating student-centered learning and pedagogical purpose.

The Fig. 1 shows the adapted and revised eight knowledge areas and contents for the capstone course based on PMBOK. First of all, the knowledge areas of project cost, risk and procurement managements were integrated into the student team supporting management by teaching-staff because such those managements not only depend on the institution but also student team needs teaching-staff's sponsorship and control unlike the private firm's project. Furthermore, the project documentary management is added as a new area that is very important for student-centered learning process because students need to search and acquire information and knowledge for problem-solving by them. It should provide such those data and information for students as well as storage and manage information, outputs including documents created from other knowledge areas and references uploaded by them from various sources. Thus the adapted knowledge management from PMBOK is organized into 8 areas. The main contents of 8 areas are similar to those of PMBOK 
except the last 2 areas which are merged and new area by capstone course-specific and student-centered learning feature. Such those differences between project knowledge management for capstone course and PMBOK make appearance and function between the web-based PMS for capstone and business-use PMS based on PMBOK different apparently.

\begin{tabular}{|c|c|c|}
\hline PMBOK & $\begin{array}{l}\text { Adapted \& revised } \\
\text { knowledge areas for } \\
\text { capstone course }\end{array}$ & $\begin{array}{l}\text { Contents for } \\
\text { capstone course }\end{array}$ \\
\hline
\end{tabular}

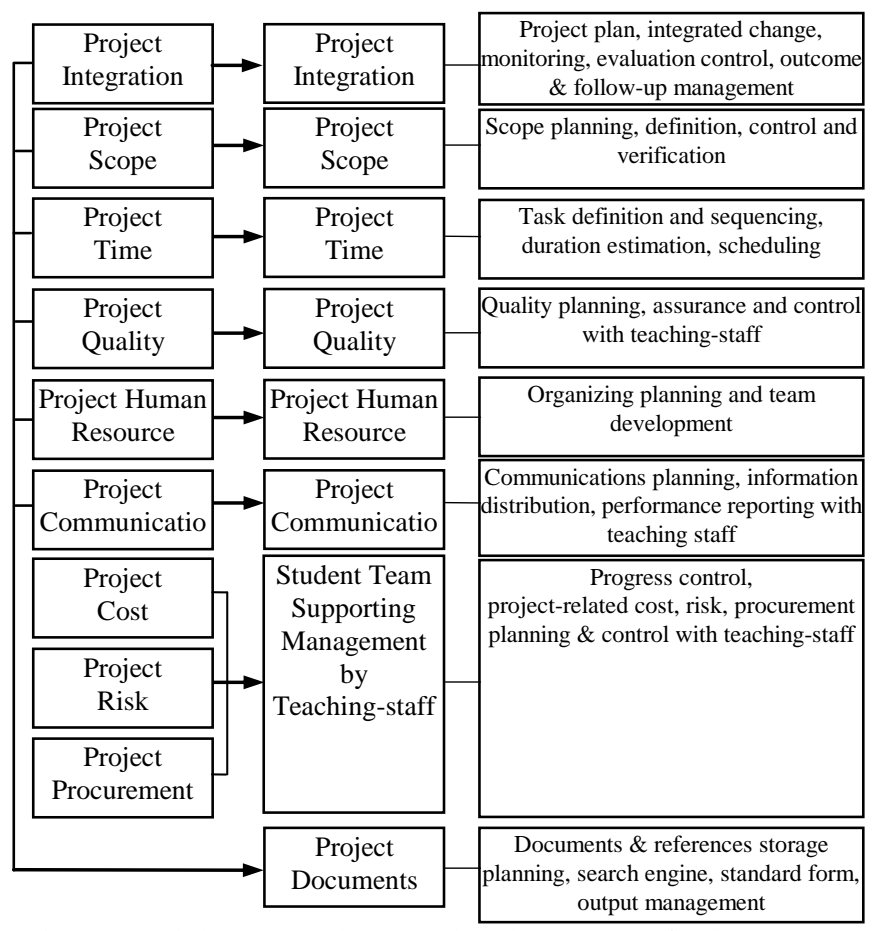

Fig. 1. Knowledge areas and contents based on PMBOK for the capstone course.

\section{B. Developing Procedure, System Architecture and Functions}

The general 4 procedures to construct the information system such as analysis, design, development and implementation are applied to develop the web-based PMS for the IE capstone course. The analysis as a preparing step includes the reviews on related references and the basic concept and necessary contents of PMS discussed in section 3.1. The second step, the design is related to the system architecture including overall appearance, structure and main functions. The Fig. 2 shows the system architecture which is designed by the adapted and revised knowledge areas from the PMBOK and was also considered the requirements of capstone course participants: a questionnaire survey for students and interviews for the teaching staff. The system architecture was designed for using and providing for the 4-type users which are a professor in charge, the advisor-to-team, students, external users like client firms and alumni. The 4-type users can access and use through the application module of the web-based PMS and produce the diverse outputs of project execution on the output module which will be stored and managed in DBMS (data base management system) module. And service module of the web-based PMS including search engine and inquiry function provides the project outputs and history of alumni, problem-solving information, methods and sources, relevant references and other information for users. To construct the system architecture and functions in the $3^{\text {rd }}$ step, we used the Windows Server 2012 R2 Standard as a web server and JSP, JAVA, HTML, Java Script, CSS as languages with Apache-tomcat, Eclipse (Eclipse IDE for Java EE Developers) as development tools and lastly Microsoft SQL Standard Edition for the DBMS. The last implementation step has to provide the completeness of the developed system through test on the accessibility to the system and on whether the data of output screen is consistent with that of DBMS as well as a subsequent work such as debugging on the programming, improving the system by feedback from the test. The last step was carried out during one semester before launching it to the capstone course.

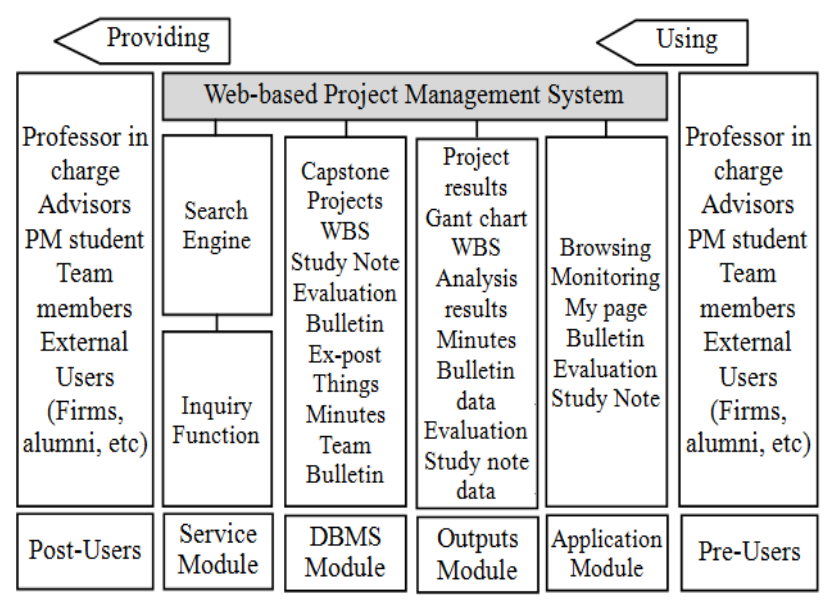

Fig. 2. The web-based PMS architecture.

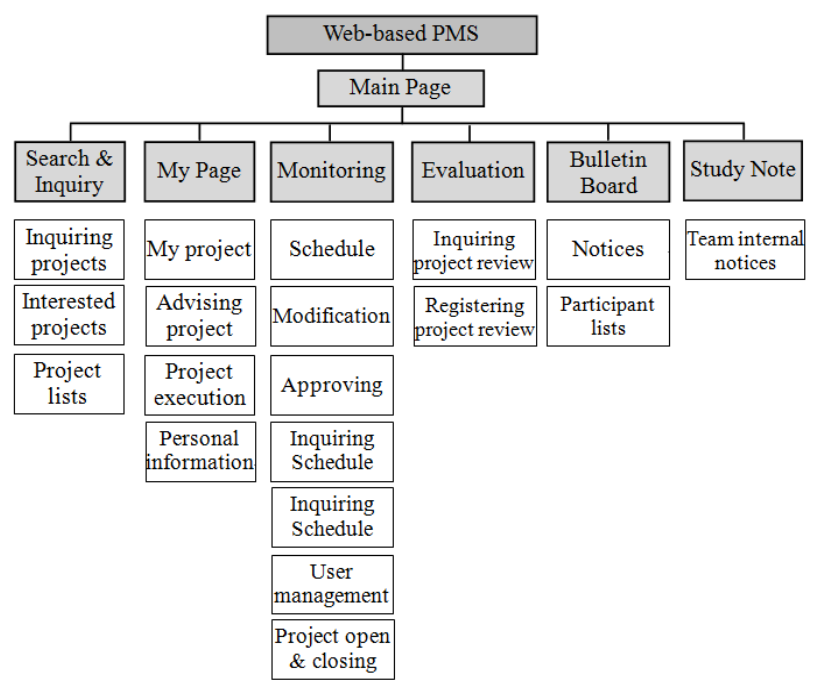

Fig. 3. The structure of main menu of the web-based PMS.

The structure of main menu of the web-based PMS is shown in Fig. 3 which is comprised of 6 submenus: Search \& inquiry, my page, Monitoring, Evaluation, Bulletin board and Study note. The functions in such those submenus cover 7 knowledge areas revised and adapted from the PMBOK in Fig. 1. The Search \& inquiry menu has several functions searching the previous capstone project outputs and history, registering the interested projects to benchmark for the student project and various projects lists including IE related projects of other universities. The second menu My page is for each team including each team's information about advisor, client firm and personal contents as well as documents produced during 
the project execution. The third menu Monitoring provides project manager, advisors and a professor in charge with control and monitoring function such as scheduling control, correction of current information, approval about tasks, project-opening and closing, etc. The forth menu Evaluation provides the proposal, interim and final review results about team projects by the faculty members and peers including grade and comments for each report. The fifth menu Bulletin board is one of communications channel for all participants in the capstone course while the Study note, unable to access by other teams and faculty members, is the only channel within the team that enables members to exchange the informal opinions of team members and foster a creative idea and problem-solving methods in an atmosphere of freedom.

And Fig. 4 describes the menu structure of the system manager which covers knowledge of student team supporting management in Fig. 1. The PMS supporting manager provides the management of overall system information, every participant's information, facilities' information including maintenance, repair and operation of department facilities and hardcopy-typed references, etc. And the most important function of the PMS supporting manager is not only to support the project execution on the web-based system technically, but also to update the project-related information including project history, evaluation, bulletin data, and follow-up projects etc.

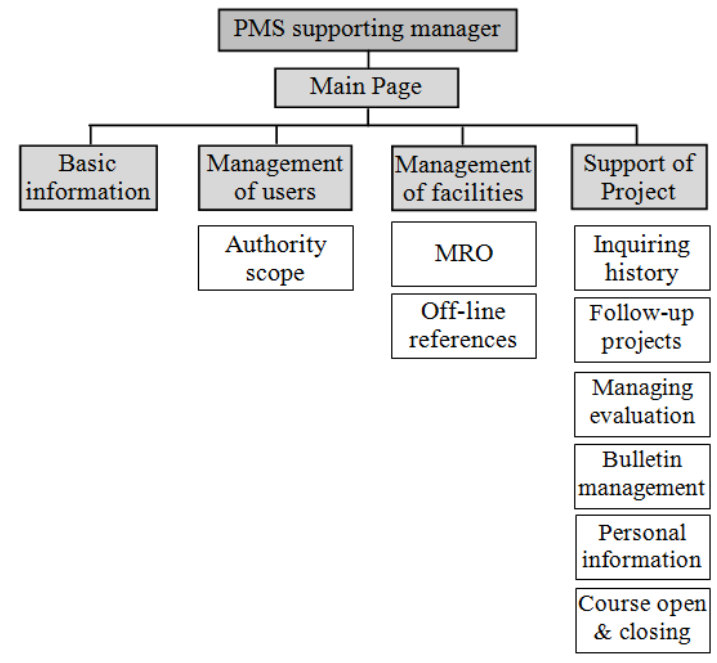

Fig. 4. The menu structure of the system manager.

\section{CONCLUSION}

The capstone course management and project execution by students using the web-based PMS are believed to be the starting point of an innovative teaching and learning strategy for student-centered learning and facilitating them to be an identity shift from student to professional engineer. Since the development of the web-based PMS for the capstone course of IE in the fall 2014, after several modifications it was implemented for the capstone course in the spring semester of 2015. Albeit the necessity and importance of the web-based PMS, it is another question whether it will be successful implementation and operation for students, teaching staff and other users because the web-based PMS using by every participants may produce new time consumption works, added efforts to learn how to use the system and there are unexpected system errors during project execution. Such those problems during using the system decrease the benefits of project management system and further impede student-centered learning which is the first objective in the course. Therefore, besides technical treatment such as repair and maintenance of the system, the theoretical and empirical studies on the PMS and the capstone course must be subsequently essential.

Future studies for theoretical aspect include pedagogical theories to boost student-centered learning in the capstone course connecting the academic class to the practical industry field. And the methods to apply such theories to the system architecture are also a target of the future studies. For the empirical studies, as learning by practicing, the usefulness and validation of web-based PMS for the IE capstone course can be tested through the survey studies on actual users such as students, alumni, teaching staff and external firms, etc. The survey information is also an important source to improve the current system.

This study aims to develop a web-based project management system based on the body of knowledge well known as project management guide and reflected the IE discipline- and course-specific characteristics. And now the system is launching and being utilized by the various participants. Although this is just beginning with many pitfalls, the system will be expected an important pedagogical property for student-centered learning and to grow a critical hub between academia and industry fields for the future engineers.

\section{ACKNOWLEDGMENT}

This research was supported by Basic Science Research Program through the National Research Foundation of Korea (NRF) funded by the Ministry of Science, ICT and future Planning (NRF-2013R1A2A2A03067925)

\section{REFERENCES}

[1] S. M. Brown and C. J. Seider, Evaluating Corporate Training: Models and Issues, Springer, 1997.

[2] C. L. Dym, A. M. Agogino, O. Eris, D. D. Frey, and L. J. Leifer, "Engineering design thinking, teaching, and learning," Journal of Engineering Education, vol. 92, no. 1, 2005, pp. 7-25.

[3] J. Lave and E. ScWenger, Situated Learning: Legitimate Peripheral Participation, New York Cambridge: University Press, 1991.

[4] A. Johri and B. M. Olds, "Situated engineering learning: Bridging engineering education research and the learning science," Journal of Engineering Education, vol. 100, no. 1, pp. 151-185.

[5] M. J. Prince and R. M. Felder, "Inductive teaching and learning methods: definitions, comparisons, and research bases," Journal of Engineering Education, vol. 95, no. 2, pp. 123-138, 2006.

[6] M. Lehmann, P. Christensen, X. Du, and M. Thrane, "Problem-oriented and project-based learning (POPBL) as an innovative learning strategy for sustainable development in engineering education," European Journal of Engineering Education, vol. 33, no. 3, pp. 283-295, 2008.

[7] A. Kolmos and E. D. Graaff, "Process of changing to PBL," Management of Change: Implementation of Problem-Based and Project-Based Learning in Engineering, Rotterdam: SENSE Publisher, pp. 31-44, 2007.

[8] D. R. Woods, "Problem-based learning: how to gain the most from PBL," Waterdown, 1994.

[9] D. L. Maskell and P. J. Grabau, "A multidisciplinary cooperative problem-based learning approach to embedded systems design," IEEE Transactions on Education, vol. 41, no. 2, pp. 101-103, 1998.

[10] R. Hadgraft, "Problem-based learning: A vital step towards a new work environment," International Journal of Engineering Education, vol. 14, no. 1, pp. 14-23, 1998. 
[11] E. Montero and M. J. González, "Student engagement in a structured problem-based approach to learning: a first-year electronic engineering study module on heat transfer," IEEE Transactions on Education, vol 52, no. 2, pp. 214-221, 2009.

[12] D. Jonassen, "Towards a design theory of problem solving learning outcomes," Educational Technology, Research and Development, vol. 48, no. 4, pp. 63-85, 2000.

[13] K. Laxman, "A conceptual framework mapping the application of information search strategies to well and ill-structured problem solving," Computers \& Education, vol. 55, no. 2, pp. 513-526, 2010.

[14] N. Hotaling, B. B. Fasse, B. F. Bost, C. D. Hermann, and C. R. Forest, "A quantitative analysis of the effects of a multidisciplinary engineering capstone design course," Journal of Engineering Education, vol. 101, no. 4, pp. 630-656, 2012.

[15] E. D. Graaff and A. Kolmos, "Characteristics of problem-based learning," International Journal of Engineering Education, vol. 19, no. 5, pp. 657-662, 2003.

[16] Project Management Institute (PMI), A Guide to the Project Management Body of Knowledge, $4^{\text {th }}$ ed., Pennsylvania: PMI, 2011.

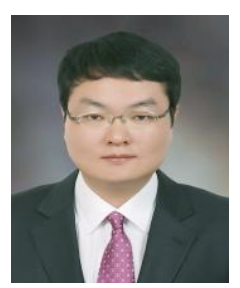

Chulhyun Kim is an assistant professor of Technology and Systems Management, Induk University. He received the degrees of BS, MS and $\mathrm{PhD}$ from Seoul National University. Before joining Induk University, he worked at IBM Korea and Korea Institute of R\&D Human Resource Development and published papers in several international journals such as Innovation-Management, Policy and Practice, Expert Systems with Applications, Service Business, ETRI Journal, etc. His research interest includes service science, R\&D management, and patent analysis.

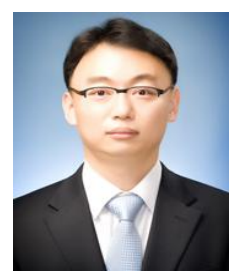

Jeonghwan Jeon is an assistant professor of the Department of Industrial and Systems Engineering, Gyeongsang National University in Korea. He received his $\mathrm{PhD}$ degree in technology management from industrial engineering at Seoul National University (SNU), Seoul, Korea. He also received a BS and MS in mechanical engineering from the Korean Advanced Institute of Technology and Science (KAIST) in Daejon, Korea. His main research interests include acquisition \& development, technology planning, technology evaluation, technology policy, and open innovation.

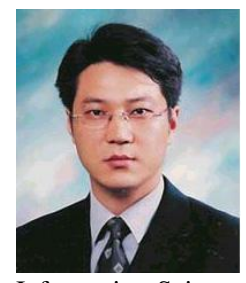

Moon-Soo Kim is a professor of the Department of Industrial \& Management Engineering, Hankuk University of Foreign Studies (HUFS) in Korea. He has experienced as a project manager at ETRI for 5 years prior to joining the university. His research focuses on technology management and its various application fields. Dr. Kim has published papers in several international journals such as Telemactics \& Informatics, Scientometrics, Technology Analysis \& Strategic Management, Omega, ETRI J, Tele. Policy and Technological Forecasting \& Social Change, etc., and also in several domestic journals. He holds a Ph.D. from Seoul National University in Korea. 